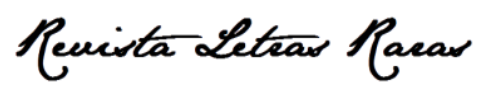

ISSN: 2317-2347 - v. 9, n. 2 (2020)

Todo o conteúdo da RLR está licenciado sob Creative Commons Atribuição 4.0 Internacional

\title{
Pensando as narrativas memoriais e pós-memoriais em tempo
}

\author{
de vulnerabilidade /
}

\section{Thinking Memorial and Postmemorial Narratives in Vulnerable}

\author{
Times
}

\section{Maria da Conceição Coelho Ferreira*}

Maria da Conceição Coelho Ferreira é maîtresse de conférences (professora adjunta) da Université Lumière Lyon 2 desde 2008. Com um doutorado em Literatura brasileira pela Université Sorbonne Nouvelle - Paris 3, estudou as crenças religiosas e políticas em Grande Sertão: Veredas, de João Guimarães Rosa. Sua pesquisa atual relaciona-se à memória da ditadura na literatura brasileira contemporânea e ao papel exercido pelo direito no resgate dessa memória. Para tal, o enfoque na política e na religião é essencial para se compreender o papel exercido pela literatura para tal preservação.

\section{(iD https://orcid.org/0000-0002-0568-470X}

\section{Ilana Heineberg*}

llana Heineberg é maîtresse de conférences (professora adjunta) de literatura e cultura brasileiras na Université Bordeaux Montaigne desde 2006. Em seu doutoramento na Université de la Sorbonne Nouvelle - Paris 3 estudou o papel do folhetim na formação do romance brasileiro no século XIX. Mais recentemente tem trabalhado sobre a circulação e a tradução do romance brasileiro na França e sobre diversos autores contemporâneos. Questões ligadas à pós-memória, ao exílio e às situações de trânsito e mobilidades estão no centro de seus interesses atuais.

\section{iD http://orcid.org/0000-0002-4158-0115}

\section{Sandra Assunção**t}

Professora Adjunta de Literatura e Cultura Brasileiras no Departamento de estudos lusófonos da Université Paris Nanterre. Doutora em Estudos Lusófonos pela Université Sorbonne Nouvelle-Paris 3 e Universidade de São Paulo (cotutela). Possui Graduação em Letras com habilitação em Língua portuguesa e Língua francesa pela Universidade de São Paulo (2001), Mestrado em Estudos lusófonos pela Université Sorbonne Nouvelle-Paris 3 (2003). Pesquisadora de literatura brasileira, abordando os temas literatura e migração; literatura e memória; margem e periferia; poéticas da infância.

(iD) https://orcid.org/0000-0003-0991-424X

Recebido: 22 mai. 2020. Aprovado: 23 mai. 2020

\footnotetext{
* $\$ maria.da.conceicao.coelho-ferreira@univ-lyon2.fr

** $\triangle$ llana.Heineberg@u-bordeaux-montaigne.fr

*** sassuncao@parisnanterre.fr

doi http://dx.doi.org/10.35572/rlr.v9i2.1803
} 


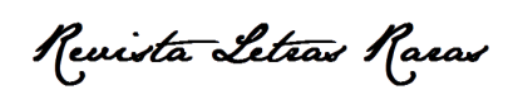

ISSN: 2317-2347 - v. 9, n. 2 (2020)

Todo o conteúdo da RLR está licenciado sob Creative Commons Atribuição 4.0 Internacional

\section{Como citar este artigo:}

HEINEBERG, Ilana; FERREIRA, Conceição Coelho; ASSUNÇÃO, Sandra. Pensando as narrativas memoriais e pós-memoriais em tempo de vulnerabilidade. Revista Letras Raras, v. 9, n. 2, p. 10-21 jun. 2020.

RESUMO

A partir de um levantamento da contribuição de grandes teóricos que pensaram a memória e a complexa representação do passado, buscamos discutir o papel da narração e da ficção como mediadoras na interpretação do vivido. A fiabilidade da reconstrução do passado é posta em causa, o que nos leva a refletir sobre a noção de testemunho e a questão da verdade a ele inerente. Cotejar memória oficial e narrativas individuais faz-se necessário a fim de se contrapor discursos meta-narrativos autoritários a uma história mais polifônica, que enseja a compreensão e a superação de traumas. Veremos também como a reflexão teórica a respeito da transmissão intergeracional de memórias traumáticas oferece ferramentas para a interpretação de obras da chamada geração pós-memorial. A partir dessas considerações, e diante da crise sanitária mundial que nos coloca em posição de testemunhas vulneráveis de uma catástrofe, somos levados a refletir sobre o futuro a partir de um olhar retrospectivo do trauma.

PALAVRAS-CHAVE: memória; pós-memória; narrativa literária; escrita do trauma; testemunho

\section{ABSTRACT}

Based on the contribution of memory theorists who thought about the complex representation of the past, we aim to discuss the role of narration and fiction as mediators in the interpretation of the lived experience. The reliability of the reconstruction of the past is called into question, which leads us to reflect on the notion of testimony and the question of the truth inherent to it. To compare official memory and individual narratives is essential to oppose authoritarian metanarrative discourses to a more polyphonic story, which leads, in our view, to the understanding and overcoming of traumas. We will also see how the theoretical reflection on the intergenerational transmission of traumatic memories offers tools for the interpretation of works of the so-called post-memorial generation. Based on these considerations, and given the global health crisis that places us in the position of vulnerable witnesses to a catastrophe, we are led to think about the future from a retrospective look at the trauma.

KEYWORDS: memory; postmemory; literary narratives; writing of trauma; testimony

\section{Introdução}

Contar a vida é um ato de memória; memória esta que, segundo Henri Bergson, são resquícios de imagens que influenciam nossa percepção do presente a ponto de sobrepor-se a ele, enriquecendo a experiência vivida através da experiência adquirida (BERGSON, 1965). Ao olharmos o passado à luz do presente, a memória surge como feixe de lembranças e de sensações que ganham existência quando transformadas em histórias, trazendo à tona o que foi inclusive negado.

Matéria de reflexão para grandes nomes da filosofia e da literatura, a memória e a sua escrita são o tema do volume 9 da Revista Letras Raras que almeja dar continuidade à reflexão 


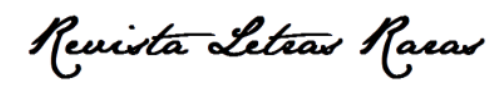

ISSN: $2317-2347$ - v. 9 , n. 2 (2020)

Todo o conteúdo da RLR está licenciado sob Creative Commons Atribuição 4.0 Internacional

sobre as possíveis formas de escrever o passado, considerando a sua dimensão traumática e intergeracional, dentro de um escopo de narrativas majoritariamente contemporâneas. Como (re)escrever e o que contar do passado? Qual é o papel da memória na reconstrução do vivido e já perdido? Qual sua parte de verdade e de ficção?

Sistemas simbólicos de representação da memória coletiva e individual, a história e a literatura são narrativas que questionam o passado através de sua materialização, independente do seu método. Almejando estar mais próxima dos fatos ou arrematando-os pelo poder da imaginação, ambas propõem uma ressignificação do passado através de sua reconfiguração discursiva (HUTCHEON, 1991). Assim, o passado não se restringe ao factual, mas se caracteriza pelo modo como os acontecimentos repercutem no indivíduo.

Guerra de memórias, segundo François Dosse ${ }^{1}$, ou obsessão pelo passado, como Henry Rousso entende representar o imperativo "dever de memória", as diferentes versões que podemos ter do que passou e da sua permanência no presente, tanto podem resvalar para um excesso de memória, quanto para uma memória esvaziada. Entre o Holocausto como memória matricial e negativa (ROUSSO, 2016) e as leis de anistia como memórias impedidas (RICOEUR, 2000), onde situar as narrativas memoriais e pós-memoriais e qual é o papel por elas desempenhado? Nesse paradoxo memorial que as sociedades do século XXI atualizam exacerbar a memória, cristalizando-a através de memoriais e rituais cívicos, ou negá-la através de métodos que impeçam as sociedades de expurgar o passado traumático -, transitam os discursos epistêmicos sobre o passado, da história à literatura.

Excesso de memória ou não, a compreensão e a permanência do passado no presente demandam que o fluxo caótico da vida seja transformado em narrativa. Se a vida é uma história potencial em busca de um bom narrador, é porque nossa existência humana, e não apenas biológica, só existe, quando a transformamos em uma história compreensível, já que contada. $\mathrm{Na}$ história de que somos narradores nada é estático, os fatos sendo constantemente reinterpretados à luz de um diálogo entre o tempo individual e a dimensão histórico-cultural em

\footnotetext{
${ }^{1}$ Em seu estudo "L'histoire à l'épreuve de la guerre des mémoires" (2008), o historiador e epistemólogo François Dosse aponta para a concorrência de memórias vivida na atualidade entre os representantes políticos, que tentam impor aos historiadores o modo como a memória deve ser transmitida, e uma parcela de historiadores, que exigem o direito de esquecimento e de não transmissão do passado. Entre as duas vertentes, Dosse se posiciona do lado daqueles que acreditam num enriquecimento da história pela contribuição dada pelas memórias plurais (como a das mulheres e de grupos sociais excluídos) (DOSSE, 2008).
} 


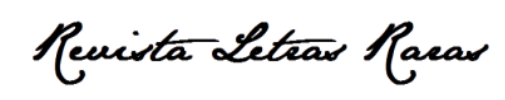

ISSN: 2317-2347 - v. 9, n. 2 (2020)

Todo o conteúdo da RLR está licenciado sob Creative Commons Atribuição 4.0 Internacional

que estamos inseridos, constituindo, assim, nossa identidade narrativa, como definiu Ricœur (2008). Para o filósofo francês, a ficção funciona como mediador inegável na interpretação dos acontecimentos vividos, já que o passado só existe porque contado.

Este artigo busca, portanto, ancorar as reflexões discutidas em todos os textos do dossiê, a partir do olhar de pensadores da memória e sobre a complexa representação do passado; e, então, procuramos discutir o papel da narração e da fiç̧ão como mediadoras na interpretação do vivido. A confiabilidade da reconstrução do passado é posta em causa, o que nos leva a refletir sobre a noção de testemunho e a questão da verdade a ele inerente. Cotejar memória oficial e narrativas individuais faz-se necessário a fim de se contrapor discursos metanarrativos autoritários a uma história mais polifônica, que enseja a compreensão e a superação de traumas.

\section{Narrar o passado e superar o trauma}

Este dossiê interroga um corpus de obras romanescas contemporâneas, que tem como ponto comum a transposição de uma memória dolorosa para a narrativa literária, por vezes ocultada, por vezes excluída - da memória coletiva ou da história oficial, e que deve ser elaborada. Em paralelo às problemáticas que a história e o direito encontram para identificar a "verdade" dos fatos históricos, certos artigos enfocam os protocolos urdidos pela ficção ou pela própria história, a fim de utilizar o testemunho em todas as suas formas (oralidade/escrita), as suas funções, os seus conteúdos, sua recepção (formal ou informal) e o lugar que ocupa na construção da memória coletiva, levando-se em conta o valor e a validade para os destinatários.

Sobre a entrada do testemunho em literatura, Jean-Louis Jeannelle (2004) afirma:

0 modelo testemunhal encontra-se assim entre uma série de opções antagônicas, levadas ao extremo: solicitado e recolhido de maneira sistemática por nossas sociedades preocupadas em preservar os rastros do passado, ele aparece como o lugar por excelência de confrontação ao indizível, ao insondável; vetor social essencial de convicção, ele é o objeto mais exposto à desconfiança, radicalizado de maneira deliberada no caso do negacionismo; apesar do seu estatuto de narrativa factual e da importância que lhe é conferida dada a exigência de adequação referencial, ele investe- 


\section{Reuivta Letear Pacas}

ISSN: $2317-2347$ - v. 9 , n. 2 (2020)

Todo o conteúdo da RLR está licenciado sob Creative Commons Atribuição 4.0 Internacional

se de um grande potencial estético, situando-se em certos casos nos limites da ficção, presente tanto como uma ameaça quanto como uma fonte de renovação. (JEANNELLE, 2004, p. 90, tradução nossa)2

Beatriz Sarlo (2007, p. 17), por sua vez, sustenta que "não há testemunho sem experiência, mas tampouco há experiência sem narração", porquanto a narração teria a capacidade de criar uma nova temporalidade para a experiência.

Se à ficção pode ser dada a função mediadora entre o curso ininterrupto dos acontecimentos e o sentido que podemos dar à nossa vida - tendo em vista a qualidade prénarrativa da experiência humana -, a ela também poderão ser atribuídas novas formas de narrar o passado, que entrem em concorrência com os discursos oficiais e sob a ótica de vozes nacionais "ex-cêntricas" (HUTCHEON, 1991, cap.4). Se, como afirma Maurice Halbwachs (1997), cada memória individual é um ponto de vista sobre a memória coletiva, a presentificação do passado seria ainda mais rica, se apresentada por uma perspectiva múltipla sobre um mesmo acontecimento histórico. Já que o passado não passou, o que os discursos sobre ele nos trazem, através dos seus vestígios no presente (HUTCHEON, 1991), é o seu devir (CERTEAU, apud DOSSE, 2008). Até que ponto as memórias individuais tecem a memória coletiva ou, ao menos, auxiliam-na na reconstituição de um passado, muitas vezes escamoteado? Em que medida as memórias familiares e individuais, ainda que ficcionalizadas, questionam e contradizem as narrativas oficiais?

Como nos lembra Hutcheon (1991, p. 60), "o processo de narrativização veio a ser considerado como uma forma essencial de compreensão humana, de imposição do sentido e de coerência formal ao caos dos acontecimentos". De fato, os relatos memoriais, quer sobre a nação, quer no tocante ao foro privado, por um viés histórico ou ficcional, são construções discursivas em torno dos vestígios herdados que só se diferenciam pelo modo como escolhemos contá-los. Contrapor e elucidar a memória oficial, através de narrativas individuais, significa

\footnotetext{
2 "Le modèle testimonial est ainsi pris dans une série d'options antagonistes, tendues à l'extrême: sollicité et recueilli de manière systématique par nos sociétés soucieuses de préserver les traces du révolu, il apparaît comme le lieu même de la confrontation à l'indicible, à l'insondable; vecteur social essentiel de la conviction, il est l'objet le plus exposé au soupçon, radicalise de manière délibérée dans le cas du négationnisme; en dépit de son statut de récit factuel et de l'importance qu'on y accorde à l'exigence d'adéquation référentielle, il est investi d'un grand potentiel esthétique, se situant dans certains cas aux limites de la fiction, présente à la fois comme une menace et comme une source de renouvellement".
} 


\section{Reuista Letras Pacas}

ISSN: $2317-2347$ - v. 9 , n. 2 (2020)

Todo o conteúdo da RLR está licenciado sob Creative Commons Atribuição 4.0 Internacional

desafiar discursos meta-narrativos autoritários dando lugar a uma história mais polifônica e aberta ao "ex-cêntrico".

Diante do exposto, nota-se, pois, a necessidade do exercício de memória, que poderia ser visto como possibilidade de superação de toda experiência traumática. Em psicanálise, para que um acontecimento provoque um trauma, é necessário que o sujeito se sinta ameaçado na própria existência, impotente face à realidade. $O$ horror ao real bloquearia os mecanismos que dariam uma dimensão psíquica à experiência vivida. Em paralelo, o sujeito conseguiria abstrairse da experiência traumática através do seu recalque. Como consequência, notar-se-ia um empobrecimento da psique afetada que, devido ao trauma, se vê impossibilitada de estabelecer relações afetivas e de tecer conexões entre os fatos.

Assim, devido a uma experiência traumática, o pensamento e os afetos se veriam abalados. Uma vez que a função de ligação, simbolização e de elaboração é reprimida, esta é substituída pela repetição dolorosa do ato traumático e das imagens mentais a ele associadas. Privado dos movimentos psíquicos naturais, o sujeito não vê outra alternativa, senão a de pulsão de morte (FREUD, 1992), com a tendência a restaurar um estado anterior ao horror, a fim de diminuir a tensão psíquica no qual estaria imerso.

A teoria psicanalítica explica ainda que, contrariamente ao conflito neurótico, a experiência traumática deixa o sujeito sem voz, impossibilitado de transpor no discurso o vivido, tornando-se assim, esta, uma experiência aniquiladora, cuja única saída é a autodestruição. É assim que a paralisia de mecanismos psíquicos essenciais decorrente do trauma realiza, de maneira individual, o que regimes totalitários tendem a obter, num plano coletivo: quando a diminuição do espontâneo se dá em favor de uma ordem na qual o repetitivo sobrepõe-se ao evolutivo, com o consequente controle dos movimentos criativos, impõe-se, inevitavelmente, um entrave à autonomia do sujeito. Não é de se espantar que ditadores sejam devotos de desfiles militares e que manifestem aversão a artistas e escritores, refratários a toda forma de censura e controle. A arte, e a literatura em particular, como verbalização de um pensamento que não se quer calar, mostra a via de saída da dinâmica mortífera que subjuga o sujeito vítima de um trauma.

É fato que a linguagem articulada, assim como a arte, são traços marcantes e específicos do ser humano. Vale ressaltar que todo processo criador passa pela capacidade de 0 


\section{Reuista Letear Pacar}

ISSN: $2317-2347$ - v. 9 , n. 2 (2020)

Todo o conteúdo da RLR está licenciado sob Creative Commons Atribuição 4.0 Internacional

psiquismo simbolizar e elaborar o que constitui a memória de uma cultura, ou aquilo que foi escamoteado por essa mesma cultura, numa relação e reorganização das representações dos afetos e dos elementos da realidade exterior. Se estes mecanismos se encontram presos a um estado pós-traumático, sua criatividade natural encontra-se inibida ou mesmo bloqueada.

A criatividade entretém uma complexa relação com as pulsões de vida e de morte. Se, por um lado, a criação precisa de um vazio para se manifestar, por outro lado, ela se sustenta num trabalho de elaboração psíquica, que implica numa dinâmica de ligação, de associação e de simbolização, cujo suporte é a pulsão de vida. $O$ trauma, que serve à pulsão de morte, tem um efeito anticriativo. Colocar no branco do papel, vestígios da dor, que se risca, se apaga e se reescreve, torna a escrita o melhor meio de vencê-lo, posto que a ambiguidade do trauma é inerente à sua própria condição: fato difícil de ser nomeado e que, no entanto, precisa ser exposto. Na falta do "emplastro" jurídico do julgamento (FELMAN, 2014) que remediaria o trauma causado por um passado sombrio (ditatorial, no caso do Brasil, impossibilitado pela Lei de Anistia de 1979), a ficção contemporânea parece querer abrir espaço a esse tipo de discurso memorial em todas as suas vertentes.

Considerando que toda memória tem sua parte de imaginação ou de ficção e que a narrativa que permite transmiti-la é inevitavelmente uma construção textual, as questões da autenticidade dos fatos, da sua retransmissão e da sua veracidade se colocam de maneira ainda mais aguda quando se trata de uma memória que não é própria, mas inter ou transgeracional. Se a narrativa memorial tematiza muitas vezes mais incisivamente as falhas da memória do que os fatos em si, o que dizer quando a memória foi herdada dos pais e avós ou ainda silenciada por estes? E sobretudo, como a narrativa literária e a teoria dão conta dessa memória de segundo grau ou dessa memória indireta?

A comparatista estadunidense Marianne Hirsch forjou nos anos 1990 o conceito de "pósmemória" para analisar como artistas das gerações seguintes ao Holocausto representam a experiência traumática dos seus antepassados. Sendo ela própria filha de judeus romenos, sobreviventes de campos de concentração nazistas, e encontrando-se na posição de testemunha indireta, sua teoria pós-memorial se alinha a uma guinada subjetiva das ciências humanas e sociais (SARLO, 2007, capítulo 5). 


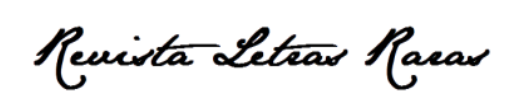

ISSN: 2317-2347 - v. 9, n. 2 (2020)

Todo o conteúdo da RLR está licenciado sob Creative Commons Atribuição 4.0 Internacional

Se em Family Frames: Photography, Narration and Postmemory, Hirsch já apontava para a possibilidade de empregar o conceito em "outras segundas gerações" (HIRSCH, 1997, p. 22), a partir de The Generation of Postmemory: Writing and Visual Culture After the Holocaust esta possibilidade torna-se concreta através da sua proposta de trabalhar com "histórias conectadas", ou seja, "dialogando com inúmeros outros contextos de transferência traumática que podem ser entendidos como pós-memória"3 (HIRSCH, 2012, p. 18, tradução nossa). Entre os exemplos citados pela autora: a escravidão africana no continente americano, a guerra do Vietnã, o Apartheid na África do Sul, o genocídio em Ruanda e as ditaduras latino-americanas. Ao relacionar, de um lado, diferentes contextos históricos e nacionais com um mecanismo semelhante de transferência memorial e, de outro, a transmissão vertical que se dá entre gerações com a transmissão horizontal intrageracional ou afiliativa, Hirsch aproxima-se do conceito de "memória multidirecional" formulado por Michael Rothberg (2018). Considerando essa perspectiva dialógica e a estrutura geracional de transmissão da memória ancorada em diversas formas de mediação, Hirsch define a pós-memória da seguinte forma:

O termo pós-memória descreve a relação que a "geração seguinte" mantém com o trauma cultural, coletivo e pessoal vivido por aqueles que a precederam. Ele diz respeito, portanto, a experiências das quais essa geração só pode se "lembrar" através das histórias, imagens e comportamentos em meio aos quais ela cresceu. Mas essas experiências the foram transmitidas de maneira tão profunda e afetiva que parecem constituir sua própria memória. A relação da pós-memória com o passado é, na realidade, assegurada pela mediação e não por lembranças, mas projeções, criações e investimentos imaginativos ${ }^{4}$. (HIRSCH, 2012, p. 5)

A definição coloca em primeiro plano a relação entre gerações mediada por narrativas orais, imagens e textos, suportes estes que, segundo Hirsch, são altamente projetivos porque repletos de afetividade. Ou seja, a imaginação que permite identificações inter, trans e intra geracionais responsáveis pela transmissão mnemônica também corre 0 risco de excessos justamente por serem passíveis de identificação e projeção. Encontra-se aí o que Hirsch qualifica

\footnotetext{
3 "in dialogue with numerous other contexts of traumatic transfer that can be understood as postmemory."

4 "'Postmemory' describes the relationship that the 'generation after' bears to the personal, collective, and cultural trauma of those who came before - to experience they 'remember' only by means of the stories, images, and behaviors among which they grew up. But these experiences were transmitted to them so deeply and affectively as to seem to constitute memories in their own right. Postmemory's connection to the past is thus actually mediated not by recall but by imaginative investment, projection, and creation."
}

doi http://dx.doi.org/10.35572/rlr.v9i2.1803 


\section{Reuivta Letear Pacas}

ISSN: $2317-2347$ - v. 9 , n. 2 (2020)

Todo o conteúdo da RLR está licenciado sob Creative Commons Atribuição 4.0 Internacional

de "os perigos da pós-memória" pois quando se tenta levar imagens do presente para entender 0 passado estas podem transformar-se em "telas para a memória", ou seja, telas em que "projetamos o presente, 0 atemporal, necessidades e desejos e que mascaram questões ainda não levantadas"5 (HIRSCH, 2012, p. 42).

As narrativas pós-memoriais têm incorporado essas questões teóricas. Por elas serem altamente autoreflexivas, os seus narradores e personagens muitas vezes se confundem num só sujeito que rememora a herança memorial, seja ela verbal ou não, frequentemente constituindose apenas de silêncios. Ao representar essa transmissão em gêneros altamente metatextuais como a autoficção, por exemplo, a literatura pós-memorial questiona-se sobre os limites entre real e ficção no seu próprio narrar.

Na esteira de Hirsch, a romancista, historiadora e socióloga Régine Robin (2007, p. 399) sublinha que as obras de arte pós-memoriais não buscam resgatar um "passado puro", intacto, mas, pelo contrário, constituem um espaço de transição no qual o passado é revivido e "reexperimentado". Assim, a segunda geração questiona a versão oficial do passado nacional fazendo emergir narrativas urgentes que fissuram 0 discurso nacional e requerem novas interpretações à luz de arquivos e da história familiar que, como afirmam Margarida Calafate Ribeiro e António Sousa Ribeiro (RIBEIRO; RIBEIRO, 2013, p. 29), no tocante à memória da Guerra Colonial portuguesa, "permanece confinada ao foro privado e incapaz de obter ressonância na esfera da memória pública". Catherine Coquio (2015, capítulo 2, segunda parte), por sua vez, também parte do conceito de Marianne Hirsch para abordar a engrenagem do "revezamento de testemunhas" ou de "testemunha da testemunha" numa sociedade que sofre, segundo ela, de uma "doença da verdade".

Com uma abordagem sociológica, Michael Pickering e Emily Keightley (2012, p. 121122) contribuem ao estudo da transmissão memorial num mesmo tempo (horizontal) e ao longo do tempo (vertical) com os conceitos de "imaginação mnemônica" e "comunidade de memória". A primeira permitiria a passagem entre diferentes gerações, mas também da esfera privada para a pública através da atividade artística da segunda ou da terceira geração. A partir da arte, emergiriam as "comunidades de memória", provisórias e formadas por negociações contínuas e por uma memória "ativamente partilhada".

\footnotetext{
5 "we project present, or timeless, needs and desires and which thus mask other images and other, as yet unthought or unthinkable concerns."
}

doi http://dx.doi.org/10.35572/rrr.v9i2.1803 


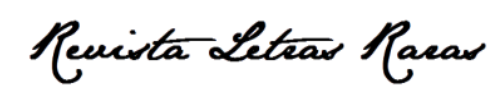

ISSN: 2317-2347 - V. 9, n. 2 (2020)

Todo o conteúdo da RLR está licenciado sob Creative Commons Atribuição 4.0 Internacional

\section{Conclusão}

O dossiê Narrativas memoriais e pós-memoriais foi preparado antes e durante a crise sanitária mundial da Covid-19. A chamada foi lançada num momento que já era de fragilidade, durante o qual os ímpetos autoritários no Brasil apontavam para a importância das narrativas memoriais e pós-memoriais, mas ainda num tempo em que não se podia suspeitar que o mundo não seria mais o mesmo em questão de meses. O término deste dossiê coincidiu com o ápice da crise, primeiramente na França, onde nos encontramos, e a seguir no Brasil. A expressão "tempo de vulnerabilidade" nos vem de Marianne Hirsch (2014) e se refere evidentemente ao período pré-Covid-19, em que as catástrofes já eram numerosas, mas não vividas em escala planetária, de maneira concomitante e com repercussões semelhantes - guardadas, evidentemente, as disparidades socioeconômicas entre países e grupos. Ora, se a vulnerabilidade decorre da própria condição humana, Hirsch acrescenta que ela é em grande parte uma imposição econômica, social e política. Nesse sentido, a comparatista propõe que se abra uma perspectiva temporal mais porosa e orientada para o futuro a partir do olhar retrospectivo do trauma. Assim, um melhor conhecimento da vulnerabilidade - tanto a compartilhada como a produzida - pode abrir "um espaço de interconexão bem como uma plataforma de reação e resistência"6 (HIRSCH, 2014, 337, tradução nossa).

Refletir sobre a memória, sua textualização e sua transmissão num momento de isolamento e angústia torna-se, na nossa opinião, caráter de urgência. Afinal o contexto excepcional atual coloca-nos imediatamente na situação de testemunhas de uma catástrofe. Mas a situação de isolamento, por outro lado, impacta a própria memória do que vivemos pela sensação de indistinção entre o tempo de trabalho e o de lazer, entre os dias e as noites que tendem a se confundir.

Face a essa situação, o filósofo e sociólogo francês Edgar Morin pergunta-se o que os cidadãos e os poderes públicos guardarão da experiência do isolamento: "Apenas uma parte?

\footnotetext{
6 "space of interconnection as well as platform for responsiveness and for resistance"

doi http://dx.doi.org/10.35572/rlr.v9i2.1803
} 


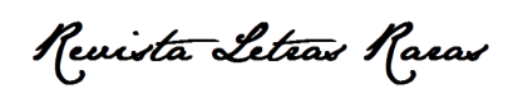

ISSN: 2317-2347 - v. 9, n. 2 (2020)

Todo o conteúdo da RLR está licenciado sob Creative Commons Atribuição 4.0 Internacional

Ou tudo será esquecido, anestesiado ou transformado em folclore?7" (TRUONG, 2020, p. 29, tradução nossa) Um coletivo de historiadores, arquivistas e sociólogos liderados pelas historiadoras Myriam Piguet e Caroline Montebello, da Universidade de Genebra, busca, desde já, interferir na memória da pandemia mundial através de um manifesto que apela às instituições e aos poderes públicos, mas também aos cidadãos, que conservem os arquivos desse evento de maneira a "dar destaque às 'vidas minúsculas', habitualmente invisíveis, mas que participam da grande história e das ciências humanas8" (PIGUET, 2020, tradução nossa).

Narrativas do confinamento, fotografias, vídeos, correspondência eletrônica, registros de hospitais, depoimentos, entrevistas e artigos de imprensa, entre muitos outros documentos, formariam esse vasto acervo da pandemia mundial. 0 manifesto lembra que "a construção de uma memória nunca é neutra", podendo "super-representar ou invisibilizar certos grupos", afinal ela é "tributária dos vestígios deixados pelos contemporâneos e depois conservados em acervos9" (PIGUET, 2020, tradução nossa). É com esse mesmo estado de espírito que refletimos sobre narrativas memoriais e pós-memoriais.

\section{Referências}

BERGSON, H. Matière et mémoire: essai sur la relation du corps à l'esprit. Paris: PUF, 1965.

COQUIO, C. Le mal de vérité ou L'utopie de la mémoire. Paris: Armand Colin, 2015.

DOSSE, F. "Michel de Certeau et l'écriture de l'histoire", in: Vingtième Siècle. Revue d'histoire, n78. Paris: Presses de Sciences Po, 2003/2.

DOSSE, F. "L'Histoire à l'épreuve de la guerre des mémoires", in: Cités (Paul Ricoeur: interprétation et reconnaissance), $n^{\circ}$ 33. Paris: PUF, 2008.

FELMAN, S. O inconsciente jurídico: Julgamentos e Traumas no século XX. São Paulo: Edipro, 2014.

FREUD, S. Inhibition, symptôme et angoisse, in: CEuvres complètes, vol. XVII. Paris: PUF, 1992.

HALBWACHS, M. La mémoire collective. Édition critique établie par Gérard Namer; préparée avec la collaboration de Marie Jaisson. Paris: Albin Michel, 1997.

\footnotetext{
7 "Une partie seulement ? Tout sera-t-il oublié, chloroformé ou folklorisé?"

8 "mettre en lumière des 'vies minuscules', d'ordinaire invisibles, mais qui participent à la grande histoire des sociétés humaines."

9 "tributaires des traces laissées par les contemporains, puis conservées dans des fonds d'archives."
} 


\section{Penista Leteas Pacas}

ISSN: $2317-2347$ - v. 9, n. 2 (2020)

Todo o conteúdo da RLR está licenciado sob Creative Commons Atribuição 4.0 Internacional

HIRSCH, M. Family Frames: Photography, Narration and Postmemory. Cambridge, Mass: Harvard University Press, 1997.

HIRSCH, M. The Generation of Postmemory: Writing and Visual Culture After the Holocaust. New York, Columbia University Press, 2012.

HIRSCH, M. Presidential Address 2014 - Connective Histories in Vulnerable Times, PMLA, v. 129 , n. 3, May 2014, p. 330-348.

HUTCHEON, L. Poética do pós-modernismo: história, teoria e ficção. Tradução de Ricardo Cruz. Rio de Janeiro: Imago editora, 1991.

JEANNELLE, J.L. Pour une histoire du genre testimonial. Littérature, Paris, n. 135, p. 87-117, 2004.

PICKERING, M. ; KEIGHTLEY E. Communities of memory and the problem of transmission. European Journal of Cultural Studies, Loughbourough, v. 16, n. 1, p. 115-131, fev. 2013.

PIGUET, M. Covid-19: pour une mémoire ordinaire de l'extraordinaire. (Tribune), Libération, edição online, 25/04/2020.

RIBEIRO, M. C.; RIBEIRO, A. S., Os netos que Salazar não teve: guerra colonial e memória de segunda geração, in Abril - Revista do Núcleo de Estudos de Literatura Portuguesa e Africana da UFF, Botucatu, v. 5, n. 11, p. 25-36, nov. 2013.

RICOEUR, P. La mémoire, l'histoire, l'oubli. Paris: éditions du Seuil, 2000.

RICOEUR, P. Écrits et conférences 1: autour de la Psychanalyse. Paris: éditions du Seuil, 2008.

ROBIN, R. Un passé d'où l'expérience s'est retirée. Ethnologie française, Paris, Presses Universitaires de France, v. 37, p. 395-400, mars 2007.

ROUSSO, H. La hantise du passé. Entretien avec Philippe Petit. Paris: Textuel, 1998.

ROUSSO, H. Face au passé. Essais sur la mémoire contemporaine. Paris: éditions Belin, 2016.

ROTHBERG, Michael. Mémoire multidirectionnelle. Repenser l'Holocauste à l'aune de la décolonisation. Tradução de Luba Jurgenson. Paris : Éditions Petra, 2018.

SARLO, B. Tempo passado: cultura da memória e guinada subjetiva. São Paulo: Companhia das Letras; Belo Horizonte: UFMG, 2007.

TRUONG, N. (entrevista). Morin: Cette crise devrait ouvrir nos esprits depuis longtemps confinés. Le Monde, Idées, Paris, p. 28-29, 19-20, abril. 2020. 